\title{
Research on Value Integration Mode of Agricultural E-Commerce Industry Chain Based on Internet of Things and Blockchain Technology
}

\author{
Xiaochun Li $\mathbb{D}^{1,2}$ and Dan Huang ${ }^{3}$ \\ ${ }^{1}$ Economic College, Hunan Agriculture University, Changsha 410128, China \\ ${ }^{2}$ Oriental Science \& Technology College, Hunan Agricultural University, Changsha 410128, China \\ ${ }^{3}$ Hunan Urban Professional College, Changsha 410137, China \\ Correspondence should be addressed to Xiaochun Li; lixiaochun116@hunau.edu.cn
}

Received 26 August 2020; Revised 27 November 2020; Accepted 16 December 2020; Published 31 December 2020

Academic Editor: Hongju Cheng

Copyright ( 92020 Xiaochun Li and Dan Huang. This is an open access article distributed under the Creative Commons Attribution License, which permits unrestricted use, distribution, and reproduction in any medium, provided the original work is properly cited.

\begin{abstract}
With the development of Internet technology, especially the application of mobile Internet technology in people's daily lives, people's lifestyles and production methods have changed, and they have brought huge economic benefits to society. In order to improve the development quality of agricultural e-commerce and expand the integration model of e-commerce, the paper analyzes the development and changes of Internet technology in the agricultural industry chain from the source to operation, production, service, security, and sales and studies the production experience model iterative upgrade. At the same time, a blockchain-based agricultural product traceability system is proposed. The system has a good supervision effect. Once recorded on the blockchain ledger, all data cannot be changed, which plays a very good traceability role for agricultural e-commerce. Actual cases show that the integrated model of agricultural e-commerce based on blockchain technology can bring huge development potential to the e-commerce industry and can improve the security and traceability of agricultural e-commerce.
\end{abstract}

\section{Introduction}

Under the new normal economy, China's economy has entered an important period of slow growth and structural adjustment. The government strongly advocates the concept of Internet of things. Internet of things has become a national strategy and has become the engine of new economic development and the driving force of innovation-driven development. The Internet has entered China for 20 years, bringing profound changes to the economic development. Integrate into agriculture, transportation, energy, and medical and education industries; at the same time, with the change and upgrading of consumer demand for products, consumer Internet is also migrating to the industrial Internet evolution. Under this situation, China's agricultural industry urgently needs to say goodbye to the extensive and inefficient mode of production in the past and catch the high-speed train which combines with modern technology.
With the industrial Internet ushered in the golden age, Internet thinking has gradually penetrated into all areas of agricultural industry. The deep integration of the agricultural industry and the internet of things has become an essential magic weapon for the transformation and upgrading of the agricultural industry. Agricultural internet, agricultural e-commerce, and rural Internet finance guided by agricultural information can significantly improve the overall efficiency of the agricultural industry chain, promote the integration of agriculture and modern technology, become the development of agricultural downstream consumption, and renew the sales channels.

Increasing popularity of network communication infrastructure and smart mobile terminals as well as recent reports from the Ali Research Institute on "New Rural People," financing of semifinished fresh e-commerce "Young Vegetable King" and dirt-flow network, and sensation of Willow Peach Promotion Project and Lenovo Control, the event of 
strategic investment in Yun farm fully reflects the concern and enthusiasm of industrial capital for the Internet of agricultural industry and e-commerce of agricultural products [1-3]. This paper mainly studies the integration mode of agricultural supply chain by analyzing the mode and deep learning algorithm and obtains a feasible integration mode.

Agriculture provides basic products to support national economic construction and development. At present, the traditional agricultural industry chain is facing the problems of low efficiency, high cost, and information asymmetry, and there are sharp fluctuations in the prices of agricultural products, agricultural products unsalable, and other phenomena. The change of e-commerce platform to agricultural industry is not only in marketing but also in rebuilding the agricultural industry chain. At present, China's agriculture has entered the era of Internet 3.0. With the wide application of Internet microelectronics and related software application platform in agriculture, the programmed participation of Internet has been realized in the circulation of agricultural resources, the management of agricultural product planting, the breeding and seedling selection of products, soil environment, and agricultural technology $[4,5]$. Change the way of agricultural development, improve the land-use rate and productivity, and promote the transformation and upgrading of agriculture, agricultural industrialization and industrialization, modernization, and other management systems for scientific integration. It is a trend of China's agricultural development in the future to make information technology widely used in agricultural production and every link of agricultural production [6]. The rest of this paper is organized as follows. Section 2 discusses the development foundation of China's agriculture, followed by agricultural industry chain reconstruction analysis and suggestions designed in Section 3. The relationship model and empirical research on network consumer behavior and e-commerce service quality are discussed in Section 4. Section 5 concludes the paper with summary and future research directions [7].

\section{Agricultural e-Commerce Structure}

Internet of things represents a new economic form. It refers to the combination of the internet and traditional industries by relying on Internet information technology, so as to complete economic transformation and upgrading by optimizing production factors, updating business system, and reconstructing business model. The "Internet plus" plan is aimed at giving full play to the advantages of the Internet, deeply integrating the Internet with traditional industries, enhancing economic productivity through industrial upgrading, and finally increasing social wealth. The change of external environment and endogenous advantages are the key factors to promote the success of industrial transformation. Under the background that the agricultural economy urgently needs to be transformed and upgraded, the mobile Internet and agricultural scale are the basis of the transformation of modern agricultural industry. The structure of agricultural ecommerce in the background is shown in Figure 1.

\section{Integration Mode of Industrial Chain Value}

The new urbanization, the deepening of the reform of the circulation system, and the food security problems urgently need to be solved make the intensive production of rural land become a trend. By the end of the year 2014, China's cultivated land circulation area has reached 380 million, accounting for $28.8 \%$ of the total contracted cultivated land. With the subsequent land transfer into a standardized and normalized stage, the scale of agricultural production is bound to speed up, and once the scale of management becomes the mainstream trend, it is bound to completely change the existing extensive mode of agricultural production and management. Compared with traditional smallscale farming, large-scale operation requires a large number of working capital, large-scale procurement of agricultural asset products, the introduction of information technology to continue to improve the permeability, rapid development of agricultural information, and the scale of land reform, new farmers, and household farmers. The gradual formation of new business entities such as farms, professional cooperatives, and modern agricultural enterprises marks the arrival of the era of the agricultural Internet, which is carrying out a comprehensive deconstruction and remodel of the agricultural chain, from the sale of agricultural means of production, letters, and so on. Information intermediary services, land flow to agricultural production, agricultural product sales, Internet giants, and agricultural enterprises with Internet thinking from the agricultural chain of active layout are trying to use the Internet to explore a variety of new agricultural industries. Business mode is shown in Figure 2.

Under the Internet mode, the agricultural industry chain will form a brand-new business model, which will provide more integration space for the trillions of markets of agricultural means of production and sales of agricultural products. Second, in the field of circulation of means of production, the e-commerce platform for agricultural means of production will gradually replace the traditional agricultural material sale system; third, in the field of product circulation, agricultural product e-commerce will also replace the original channel and form a new agricultural product trading system; fourth, in the demand side of agricultural products, consumers and industrial enterprises can achieve remote customization according to specific preferences to achieve order agricultural production; fifth, provide a complete logistics sale system in the rural market. Sixth, the demand for comprehensive services will lead to the integration of all types of business entities in the industrial chain and form unified platform operators, providing integrated platform services; at the same time, all kinds of agricultural enterprises are facing major development.

The main process formula of deep learning algorithm is as follows:

$$
S_{j}^{\prime \prime}\left(x_{i}\right)=M_{j, i-1} \frac{x_{i}-x}{h_{i}}+M_{j, i} \frac{x-x_{i-1}}{h_{i}},
$$




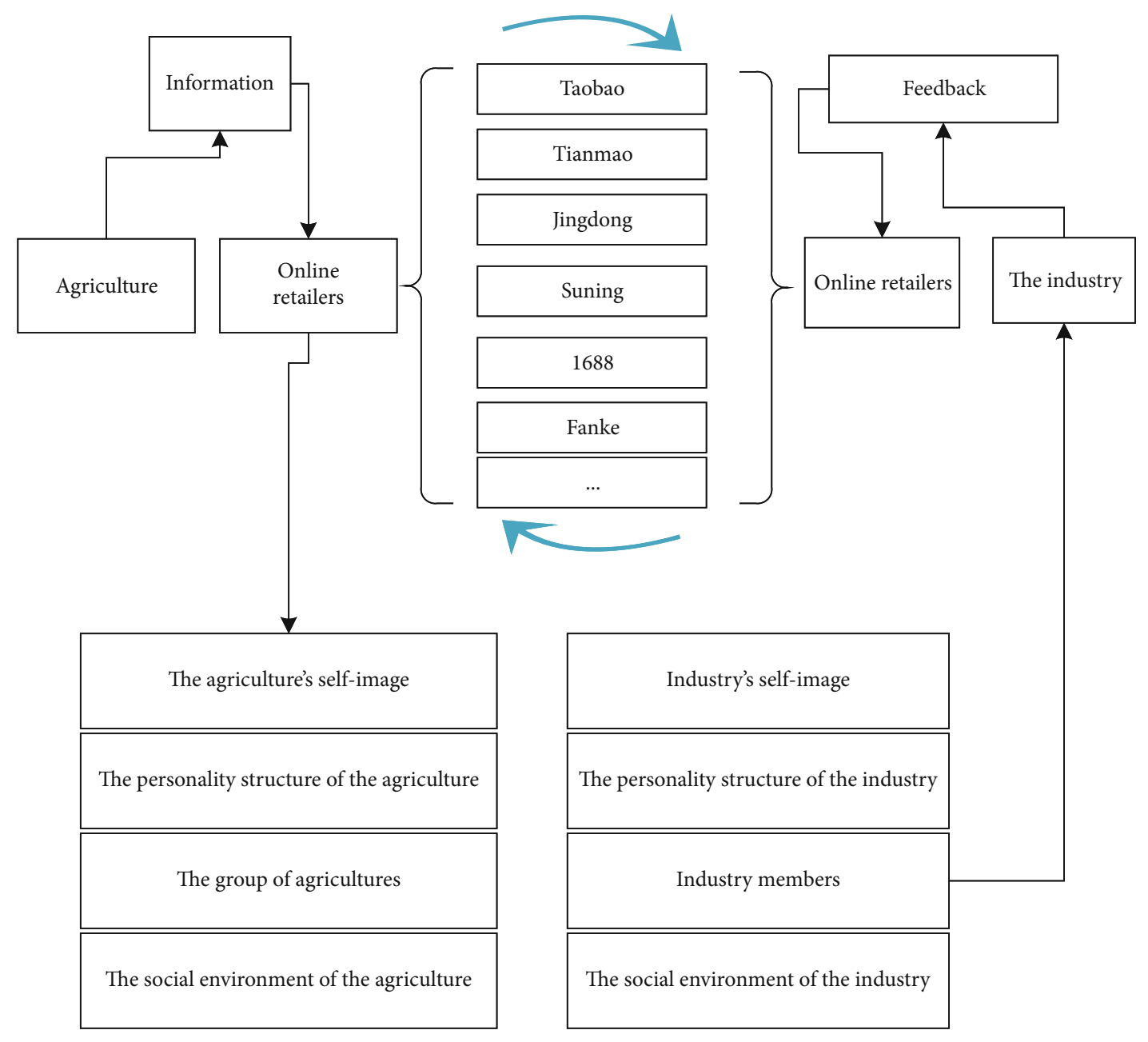

Figure 1: The structure of agricultural e-commerce.

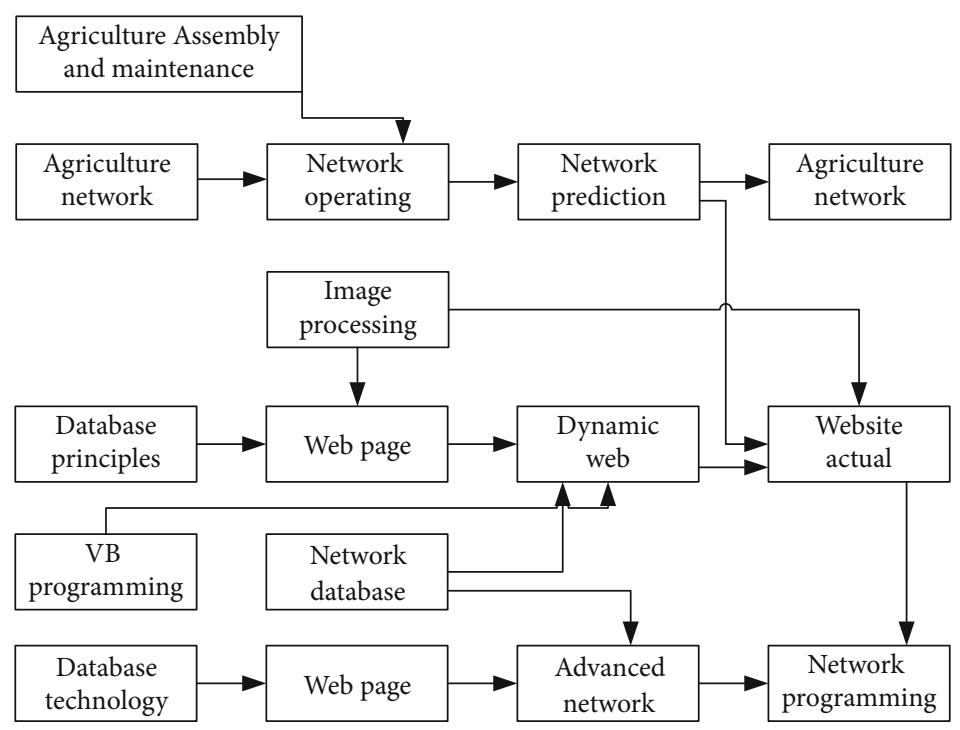

FIgUre 2: Business mode. 
in which $h_{i}=x_{i}-x_{i-1}$. By interpolation and continuity of the relationship can be the following formula:

$$
\begin{gathered}
\lambda_{i}=\frac{h_{i}}{h_{i}+h_{i+1}}, \\
\mu_{i}=1-\lambda_{i}, \\
d_{i}=\frac{6}{2 h}\left(\frac{y_{i+1}-2 y_{i}+y_{i-1}}{h}\right), \quad i=1,2 \cdots, n .
\end{gathered}
$$

Seeking $M_{j, i},\left(M_{j, 0}=M_{j, n}=0\right)$ can be solved by the chasing method, so that the cubic spline interpolation function of each subdivision of weighting vector can be obtained.

$$
\begin{gathered}
S_{j}\left(x_{i}\right)=M_{j, i-1} \frac{\left(x_{i}-x\right)^{3}}{6 h_{i}}+M_{j, i} \frac{\left(x-x_{i-1}\right)^{3}}{6 h_{i}} \\
+\left(y_{i-1}-\frac{M_{j, i-1}}{6} h_{i}^{2}\right) \frac{x_{i}-x}{h_{i}}+\left(y_{i}-\frac{M_{j, i}}{6} h_{i}^{2}\right) \\
\cdot \frac{x-x_{i-1}}{h_{i}}(i=1,2, \cdots, n), \\
\operatorname{Support}(X)=\frac{\operatorname{count}(X \subseteq T)}{|D|}, \\
R ; X \Rightarrow Y .
\end{gathered}
$$

Rule support is the ratio of the number of transactions to the total number of transactions, when the item set $X$ and $Y$ appear simultaneously, as shown in the formula (3). According to the association rules of frequent items, it is considered that the support degree of frequent itemsets is consistent with that of the rule, as shown in formula (4). Under the same conditions of the credibility of the rules, the credibility confidence of rule $R$ is the ratio of the number of transactions when $X$ and $Y$ appear at the same time and the number of transactions only when $X$ appears, as shown in formula (5), which is confidence $(X \Rightarrow Y)$.

$$
\begin{gathered}
\text { Support }[X \Rightarrow Y]=\frac{\operatorname{count}(x \cup y)}{|D|}, \\
\text { Support }[X \Rightarrow Y]=\operatorname{Support}(x \cup y)=\frac{\operatorname{count}(x \cup y)}{|D|}, \\
\operatorname{confidence}(X \Rightarrow Y)=\frac{\operatorname{support}(X \cup y)}{\operatorname{support}(X)}
\end{gathered}
$$

The main research method of the Apriori algorithm is to find all the frequent items in the object database with the minimum support and then get the association rules quickly according to the frequent items. The specific procedure is as follows: check all transaction databases and find out all the frequent items in the database. The $k$-item set is selected by its own connection to select the project set $C_{k}$. The project set of candidate options is pruned according to the frequent itemset; any one of them is a subset of frequent item. If $C_{k-1}$ is a subset of $C_{k}$, in the case of $C_{k-1} \notin L_{k-1}, C_{k} \notin L_{k}$, the set of comparisons is not a frequent subset, and the subset is deleted. Loop through the previous steps until the transaction database is not able to find a higher level of frequent itemsets. The entire data mining process ends when all the frequent items are identified by computing the associated rules that meet the needs.

With the advancement of agricultural modernization and the acceleration of land circulation, agriculture is on the way to large-scale management. With the increase of new intensive management subjects, higher requirements are put forward for the supply and service of agricultural products. In addition, the market capacity of agricultural materials in China is huge, and the scale of chemical fertilizer, seed, and feed alone exceeds trillion. In recent years, Internet giants have been "going to the countryside" to seize the rural e-commerce market, which is also conducive to the objective cultivation of rural e-commerce format, stimulate the vitality of rural e-commerce, and objectively contribute to the development of agricultural material e-commerce. In line with the general situation, the traditional agricultural material enterprises are changing their management mode of "producing one distributor and one planter." The new management mode will be married by providing better products, diversified supply of agricultural materials, and better technical services. With the more and more mature agricultural information system, the transformation of China's agricultural material producers to agricultural material service platform operators will be completed. Integration of agricultural commodity E-commerce will become an important channel and platform for agricultural commodity sales in the future. A number of agricultural commodity platforms with Internet thinking, large enough flow import, and sticky guarantee will have broad growth space. The operation mode of agricultural material Internet platform operators is shown in Figure 3.

However, as far as the current development situation is concerned, the development of China's agricultural material e-commerce has not yet formed a fixed model, and now, the more mature business models are mainly the thirdparty network sales platform (B2C) model, the third-party agricultural information platform (B2B2C) model [8]. In addition, according to the successful experience of foreign agricultural Internet development, most of the leading agricultural material enterprises in developed countries in Europe and the United States are engaged in the sale of a variety of agricultural material products, with strong integrated service capabilities [9]. Therefore, China's agricultural resource enterprises are expected to gradually develop into specialized enterprises. Flattening and integration under the promotion of online and offline (0.20) agriculture in the field of e-commerce will become modern agricultural products under the background of the Internet. [10-13].

The Internet of things is a new round of information revolution. Agricultural Internet of things has constructed the basic elements of information production. It has been recognized as the third wave of the world information industry after computers, the Internet, and mobile communication networks. It takes perception as the premise to realize the comprehensive interconnection of people, people and things, and things and things. Agricultural Internet of things (IOT) 


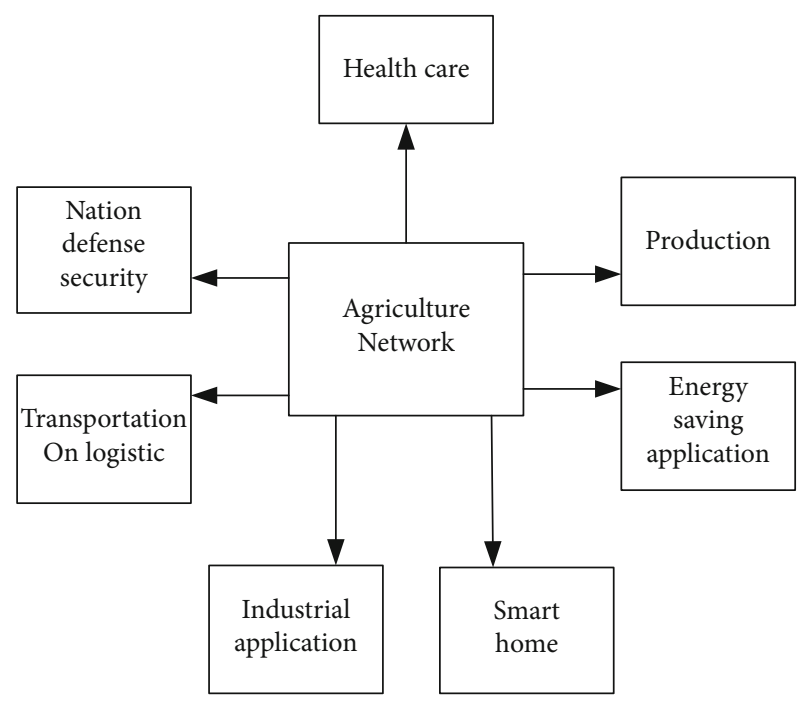

FIGURE 3: The operation mode of agricultural material Internet platform operators.

obtains crop information through sensor devices and transmits it on the basis of various networks [14]. After the central system is processed, the IOT performs remote operations. Information-based perception-network transmissiondecision support-remote control is the IOT of agriculture. The essence of agricultural information is to transform agricultural production from traditional labor cultivation to efficient production by means of information and to build a comprehensive and deep interconnection between people and things which is the core element of agricultural information. Generally speaking, all forms of agricultural information belong to the category of agricultural Internet of things, which is the soul of agricultural information [15]. Throughout the country's latest application, the agricultural Internet of things (IOT) has worked in four main areas; the specific results are shown in Figure 4.

The cross-border entry of Internet enterprises into the rural Internet shows that the emerging industrial capital is optimistic about the rural market. The data transfer model is shown in Figure 5.

The core values of the development of agricultural Internet and agricultural e-commerce lie in resolving information asymmetry, completing vertical integration of industrial chain, reducing intermediate links, reducing circulation costs and enhancing scale effect, and establishing traceable agricultural product circulation system. To solve the financing problem in the supply chain, the accumulation of transaction information can help the supplier of capital to price the risk, and the control of logistics and capital flow can reduce the default risk for the financing in the industrial chain.

Looking forward to the future, with the increase in policy support and the reform of existing agricultural production and operation, the difficulties in organizing commodity sources, high logistics costs, imperfect cold chain logistics systems, and other constraints, the development of e-commerce bottlenecks related to solving agricultural problems and business related to agriculture is expected to show explosive growth [16-18].

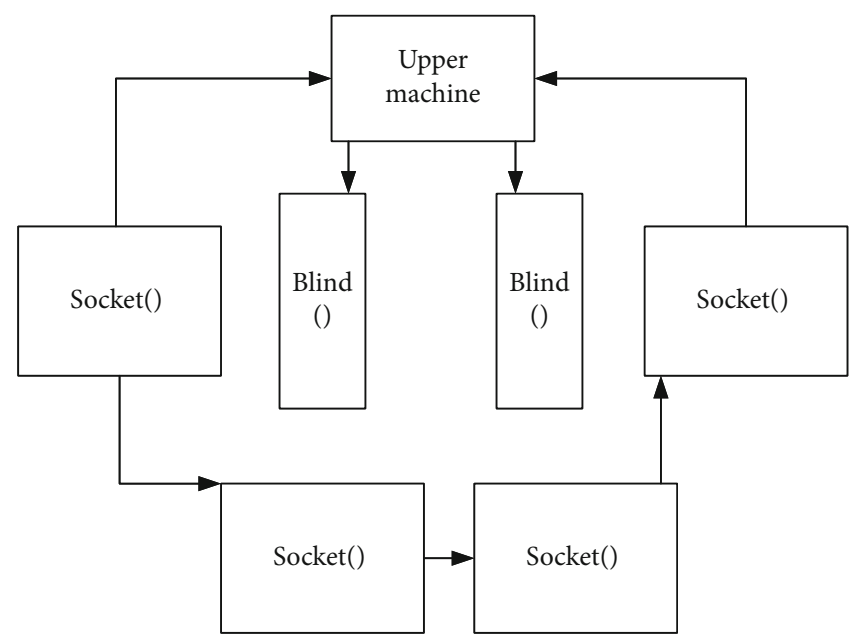

Figure 4: The agricultural Internet of things (IOT).

By the end of 2014, China's agricultural-related loans (local and foreign currencies) had a balance of 23.6 trillion yuan, accounting for 28.1 percent of all loans, an increase of 13 percent over the same period of last year; all financial institutions had a balance of 19.4 trillion in local and foreign currencies (counties and below) in rural areas, accounting for the proportion of all loans. Total loans accounted for 23.2, a year-on-year increase of $12.4 \%$. The compound growth rate of the above two indicators in the three years from 2011 to 2014 was also between 12 and 16. However, facing the "new trend" and "new normal" of the development of modern agricultural industry with scale, intensive, specialized, and modernized, the above-mentioned funds still cannot meet the growing demand for agricultural financial services. In addition, due to the underdeveloped economy, the income and expenditure of agricultural employees are extremely unstable, coupled with the lack of traditional agricultural financial service systems; these factors not only affect the enthusiasm of financial institutions to participate in agricultural finance but also limit people's access to agricultural finance. As a result, the financing channels for agricultural practitioners are very limited, and even in many places, family and friends lending and usury are still the main ones. Internet application rate in 2016 and 2017 in agriculture is shown in Figure 6.

With the realization of land mortgage rights (including homestead and farmland management rights), the problem of scarcity of collateral in the financing of agricultural enterprises has been effectively solved. Another factor restricting the development of rural finance is risk control, including subjective risk (credit difficulty) and objective risk (weather, epidemics, etc.). For the problem of difficult credit reporting, through the Internet, large data, cloud computing can also provide a more efficient solution. Among them, the fastestgrowing large data credit is to use a large number of fragmented data generated in social networks, e-commerce websites, and internet lending platforms to better collect and analyze massive, decentralized customer data, from which to obtain valuable information. Through the use of this information, we can make a more accurate assessment of the personal 


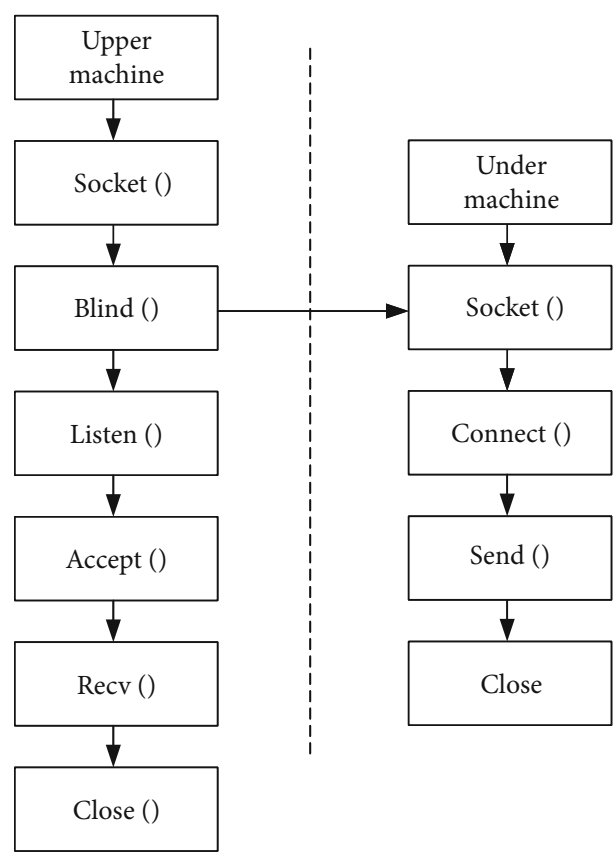

FIgURE 5: Data transfer model.

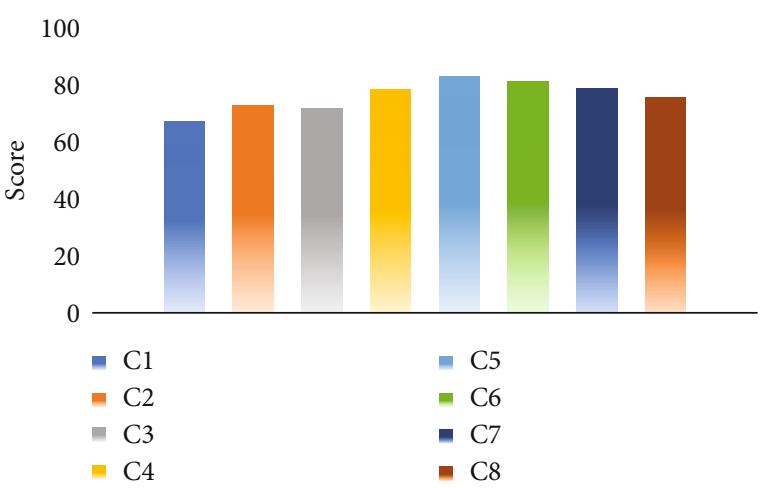

FIGURE 6: Internet application rate in 2016 and 2017 in agriculture.

credit situation; while cloud computing supports credit agencies or individuals in any location using a variety of terminals to access data storage and processing of various applications, without the need for the high cost of database development, operation, maintenance, management, and service is high. At present, some enterprises have obtained key information such as financial strength and credit evaluation of agricultural practitioners as their credit basis through the construction of large-scale data and rural Internet trading platform, which has played a practical credit effect. Based on the above reasons, with the further popularization and application of big data and cloud computing in the agricultural field, the new rural Internet financial industry will have strong vitality and will solve the problems faced by the development of agricultural modernization in the following aspects $[19,20]$.

The structure of agriculture-related finance is shown in Figure 7 [21].

The second problem that restricts the development of agriculture-related finance is the small amount of a single fund loan, the high cost of diversification, and the difficulty of management. In this regard, we can refer to the solution of e-commerce platform Jingdong. JD provides funds for farmers through credit sales, replicates JD's business model, and builds a basic social microstructure. The implementation of these measures provides a way to solve the second problem that restricts the development of agricultural finance [22].

There are three problems in restricting financial development related to agriculture: no guarantee, lack of collateral, and relying only on credit. The "Gu strategy" helps farmers increase their income by providing production technology and other support in conjunction with rural cooperatives [23]. At the same time, the country has a deep understanding of farmers, accumulated credit data, and expanded payment, insurance, and rent in rural areas through the grassroots financial service network. Leasing and other businesses provide a solution to this problem. Agricultural layout under the Internet plus background is shown in Figure 8 [24].

\section{Analysis of Agricultural Industry Chain Reconfiguration}

Production factors promote the networking of factor transactions. Land is the first element of agriculture, including seed, pesticide, fertilizer, and agriculture.

In traditional agricultural production, the demand for processing, transportation machinery, and land transfer is increasing, so the Internet technology will make use of information transparency advantages and shorten the intermediate links [25].

Agricultural technology services to promote expert service flat: agricultural production management has a certain demand for agricultural technology services to help solve various problems in agricultural production. At present, the level of agricultural technology links is still low [26].

Agricultural finance to promote public investment in agricultural investment: agriculture's demand for finance runs through the entire process of agricultural production. Internet crowds make use of the characteristics of the Internet and SNS communication, making agriculture more attractive to investment. The traditional rural financial institutions have been unable to meet the financing needs of the rapid development of agriculture, especially the traditional financial institutions that have the problems of difficult borrowing and expensive borrowing, and to a certain extent also affected the enthusiasm of farmers to borrow. With the help of Internet technology, when farmers ask for loans from the financial platform, they can complete the loan online with a single mouse. The whole process of borrowing can be completed in 2 hours from the borrower's application to the completion of the financing. This can reduce farmers' time and labor and solve problems such as "small agricultural loans" that banks are unwilling to make. The agricultural sales mode under the internet background is shown in Figure 9.

Agricultural product sales enter the $\mathrm{C} 2 \mathrm{C}$ mode of agricultural product business. At present, there are more than 30,000 agricultural e-commerce platforms in China, among which there are 3,000 agricultural e-commerce platforms. Agricultural product e-commerce must establish a good 


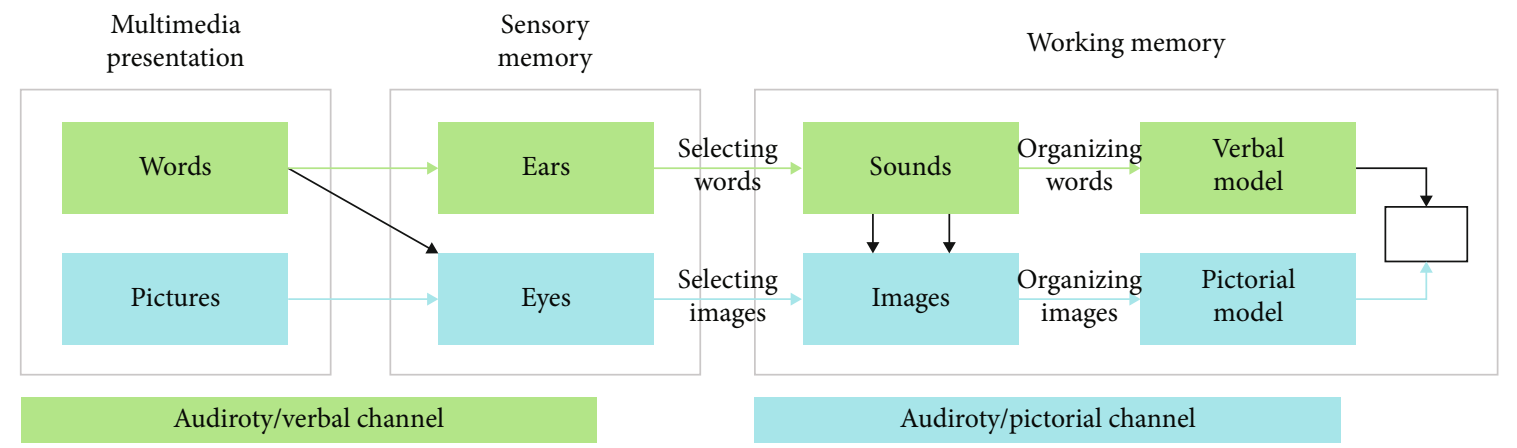

Figure 7: The structure of agriculture-related finance.

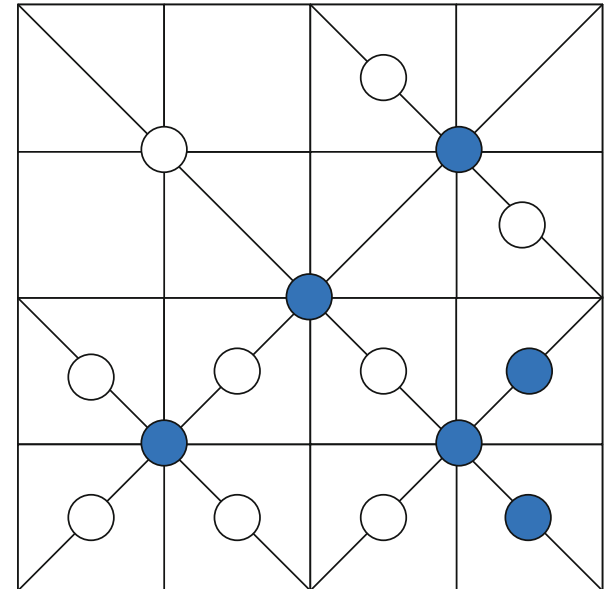

FIGURE 8: Agricultural layout under the Internet plus background.

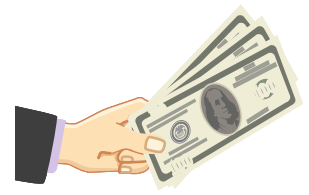

Purchasing

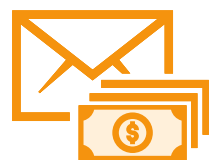

Payroll

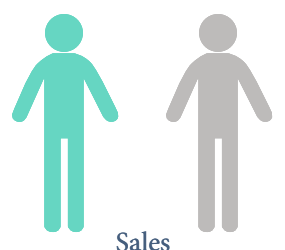

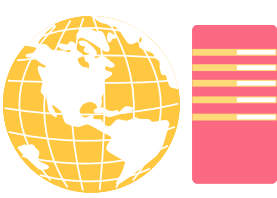

Web sever

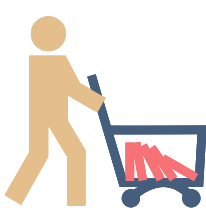

Packaging
Figure 9: The agricultural sales mode under the internet background.

shopping experience with customers in order to meet the sustained consumption and drive the relevant consumer groups. The electricity supplier eliminates all kinds of obstacles, such as information and channels of traditional sale methods.
Because farmers lack brand awareness, they do not know many high-quality agricultural products. With the help of this platform, agricultural product brands can be effectively established. Vigidani means conscience in the Uyghur language, which is the name of conscience products. This has also enabled the company to gain recognition from more and more people. The company even has repeat customers, and many customers have become loyal supporters of the brand. In just three years of its free online advertising, Vigidani became a famous agricultural product brand.

The last kilometer of rural logistics in the traditional hierarchical wholesale mode has many problems, such as high cost, loss of logistics, poor communication of information, flat and transparent information on the Internet, large-scale agricultural products trading and distribution center based on Internet technology and logistics distribution system, storage and transportation, wholesale, trading, and auction. Function can achieve real-time market transactions.

In traditional agriculture, watering, fertilizing, and taking medicine, farmers rely entirely on experience and feeling. Nowadays, facility agricultural production base should not water, fertilize, and spray; how to maintain accurate concentration, including temperature, humidity, light, and carbon dioxide concentration, through artificial intelligence technology, can be perceived in advance and analyzed according to the production situation of crops, to provide standardized production decision-making for agricultural production, which is shown in Figure 10.

Agricultural product trace system collects and analyzes the quality and safety data of various links of planting and processing through the system and monitors and controls the quality and safety of the product life cycle. Agricultural big data effectively improve the accuracy of modern agriculture. Through the big data platform, farmers can understand market demand in time and effectively reduce production costs. Particularly, the market is unpredicted; some investors are prone to blindly follow the trend, such as the rise in pig prices this year, many people on a swarm of bees into the pig farming industry, resulting in excess capacity; the second year pig prices plummeted. Through big data, farmers can clearly understand the consumption situation of the market and avoid investment risks.

Actively build local characteristics of agricultural product e-commerce platform, push fresh agricultural products on the micro direct delivery platform, guide e-commerce 


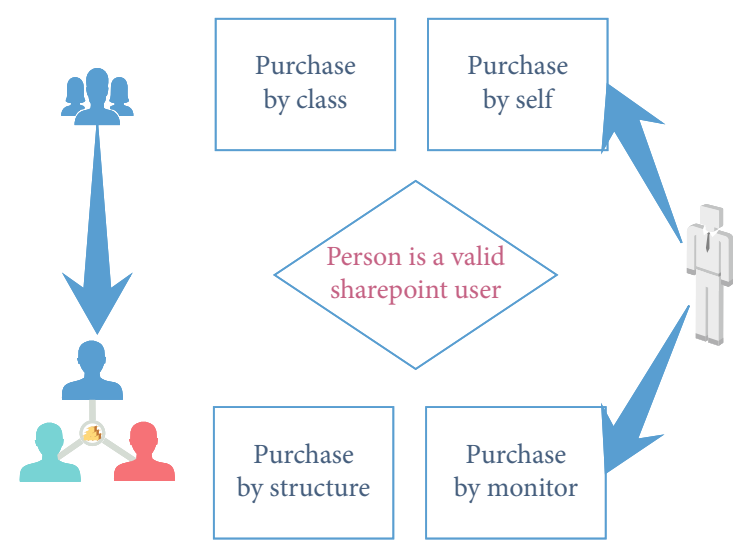

Figure 10: Standardized production decision-making for agricultural production.

enterprises to combine agricultural enterprises, and promote strong alliance. Through the Internet, farmers can be directly linked to the market, without the need for intermediate distributors, saving costs, but also conducive to improving farmers' income. Supporting large-scale and qualified enterprises develops intelligent farmland and cultivation by using sensor and Internet technologies.

Support large-scale qualified enterprises to develop the use of ERP, CRM, and other management information systems, and at the same time, improve the efficiency of enterprise operation and management, and open the chain from procurement, production to sales, and management information. These measures speed up enterprise response and improve flexible customization capabilities. Relying on cloud computing and big data technology, build a whole agricultural information integration service platform chain, improve big data analysis and data mining technology, and promote relevant information to provide reference for corporate decision-making. Promote mutual cooperation between enterprises to create a public "cloud" service platform for meteorological early warning, natural disaster early warning, major epidemic prevention and control, market price fluctuations, market feedback information, and so on.

In order to improve the hardware facilities and information technology ability training of agricultural and rural personnel, we should not only popularize computer and broadband information technology into the village but also cultivate and import technical personnel with operational ability to provide personnel support and intellectual support for the development of agricultural entrepreneurship. The steady and rapid progress of agricultural technology popularization makes agricultural technology of universities and research institutes directly face agricultural enterprises, promotes the transformation and application of scientific and technological achievements, and facilitates the promotion of agricultural products. Three algorithms running time comparison are shown in Table 1.

If the database condition was the same, but the minimum support degree was not the same, the running time of the three algorithms was tested, and the experimental results are shown in Figure 11. The operation time of the traditional Apriori algorithm is longer than that of the optimized two
TABLE 1: Three algorithms running time comparison.

\begin{tabular}{lccc}
\hline $\begin{array}{l}\text { Number of transactions } \\
\text { (bar/million) }\end{array}$ & \multicolumn{3}{c}{ Running time (ms) } \\
& Apriori & $\begin{array}{c}\text { DC- } \\
\text { Apriori }\end{array}$ & $\begin{array}{c}\text { FP- } \\
\text { Apriori }\end{array}$ \\
\hline 0.5 & 780 & 568 & 516 \\
0.6 & 950 & 458 & 432 \\
0.8 & 1121 & 554 & 478 \\
1 & 1570 & 626 & 673 \\
1.2 & 1785 & 745 & 765 \\
1.5 & 2210 & 987 & 899 \\
2 & 3180 & 1872 & 1867 \\
\hline
\end{tabular}

algorithms. Under different support degrees, the operation time also fluctuated due to the change of support degree, and the whole algorithm was in a state of instability. The other two optimization algorithms did not have such a situation. Not only the overall running time was more than the traditional Apriori algorithm segment but also there was no significant change in the operation, and the algorithm structure and operation were relatively stable. The traditional Apriori algorithm can dig out more frequent itemsets in the case of decreasing the minimum support degree, and the increase of quantity brought about the mass production of redundant rules, which made the execution time of the algorithm become longer and less efficient. The other two algorithms did not have this phenomenon and the implementation time did not have a big impact.

The results of comparison experiments for the maximum number of frequent itemsets generated by three different algorithms are shown in Figure 12. It can be seen from the comparison chart that, under the condition of the same minimum confidence, the number of mining of association rules is the traditional Apriori algorithm, and the number of the other two algorithms is similar. After the minimum confidence reduction, the mining results of the DC-Apriori algorithm proposed in this paper are the most stable and do not change the algorithm because of the fluctuations. But the FP-growth algorithm and the traditional Apriori algorithms have a lot of fluctuations, and the traditional Apriori algorithm produces a lot of useless rules that directly affect the results of the algorithm.

At present, China's rural areas are facing a major problem. A large number of young people and a strong labor force enter the cities, and only a few old people and children remain in the rural areas. By introducing entrepreneurs, it can not only stimulate the vitality of the village but also promote employment and attract more and more foreign young people to return to their hometowns to start businesses. At present, the Internet has been widely used in various industries; it also promotes the continuous integration of agriculture and other industries, such as agriculture and finance, through crowdsourcing and credit services of financial institutions, to solve many difficulties encountered in the process of agricultural development, thereby integrating integrated agricultural production, processing, and sales, while accelerating the transformation and upgrading of agricultural products. Highly value of agriculture frames is shown in Figure 13. 


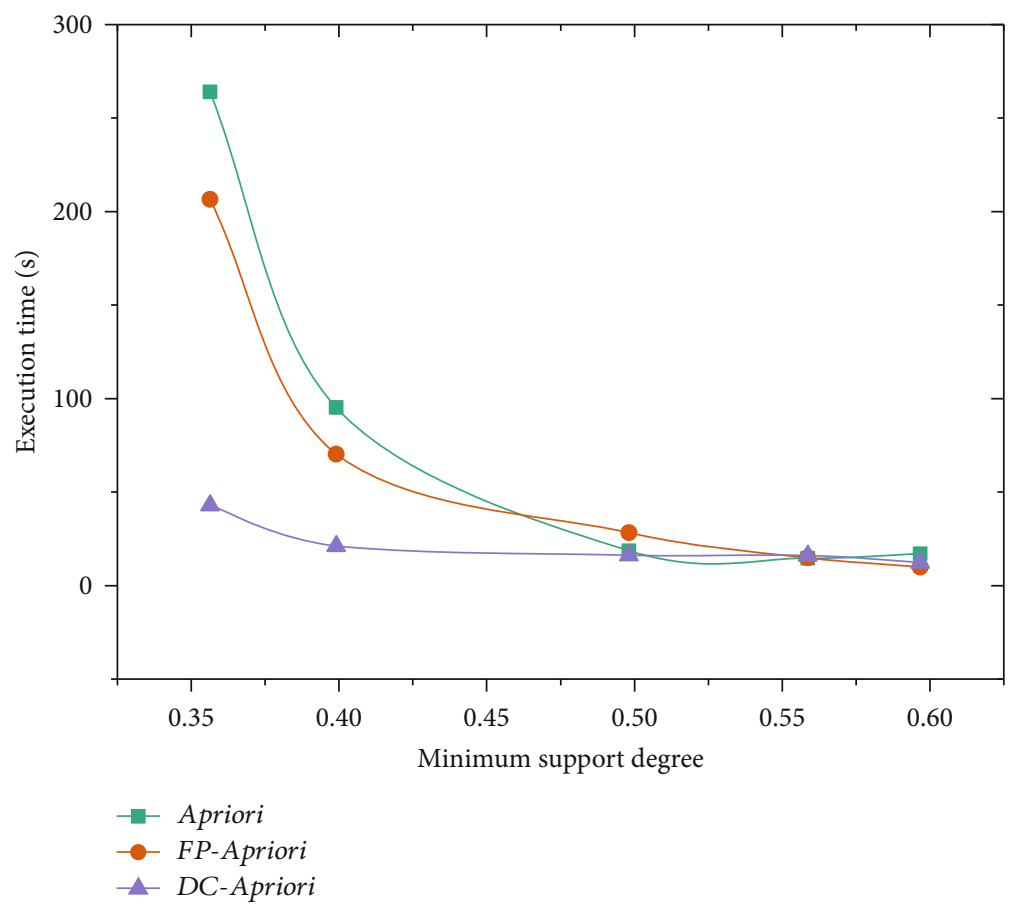

FIGURE 11: Comparison of algorithm running time.

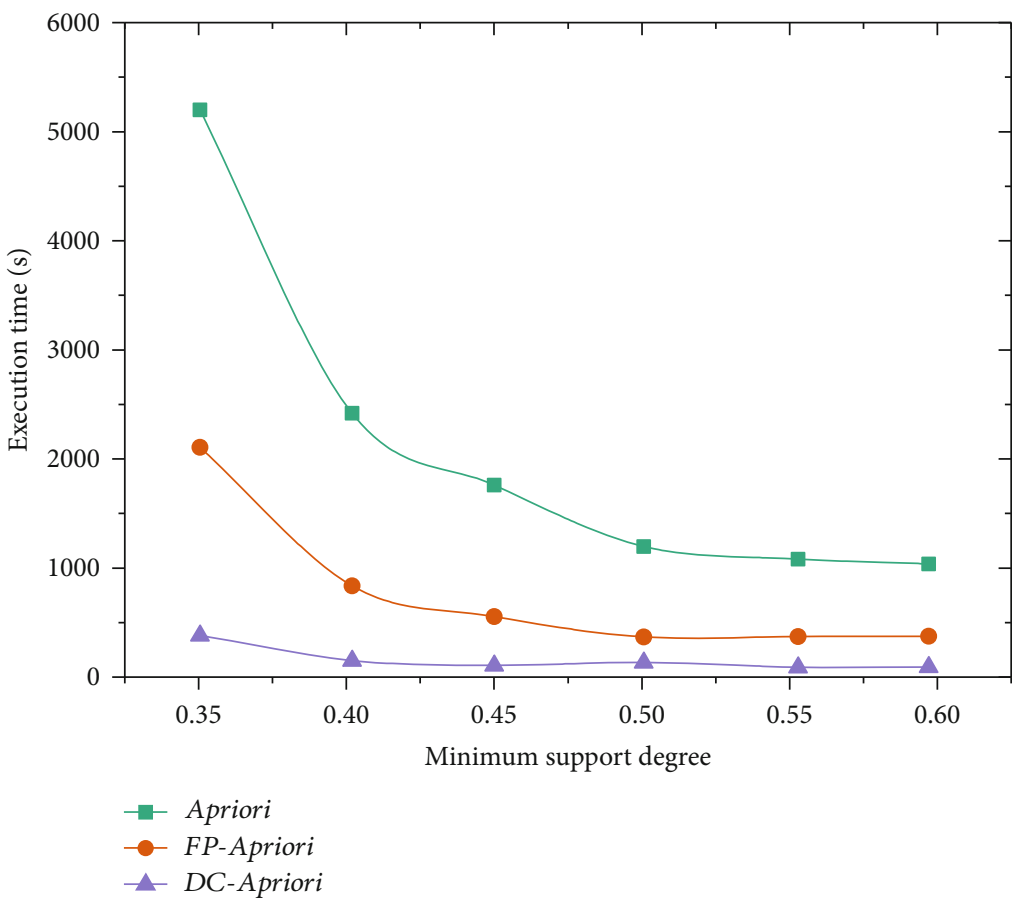

FIgURE 12: Comparison of the number of maximum frequent items.

\section{Conclusions}

The mode of operation and financing with the Internet as the carrier will be the accelerator of the development of modern agriculture in the future. "Internet-F-" restructuring of the agricultural industry chain is through the flow of information through all links, from the production of agricultural materials, circulation, marketing, services, and other aspects of agricultural production in the supply of agricultural materials, through the Internet cloud services, precision agriculture establishment of industry, large-scale data analysis, etc., to realize the upgrading of agricultural production technology, the difficulty of promoting agricultural scale, the quality and safety of agricultural products, and the realization of product value. The five perspectives of "sexualisation" comprehensively change the consumption market of 


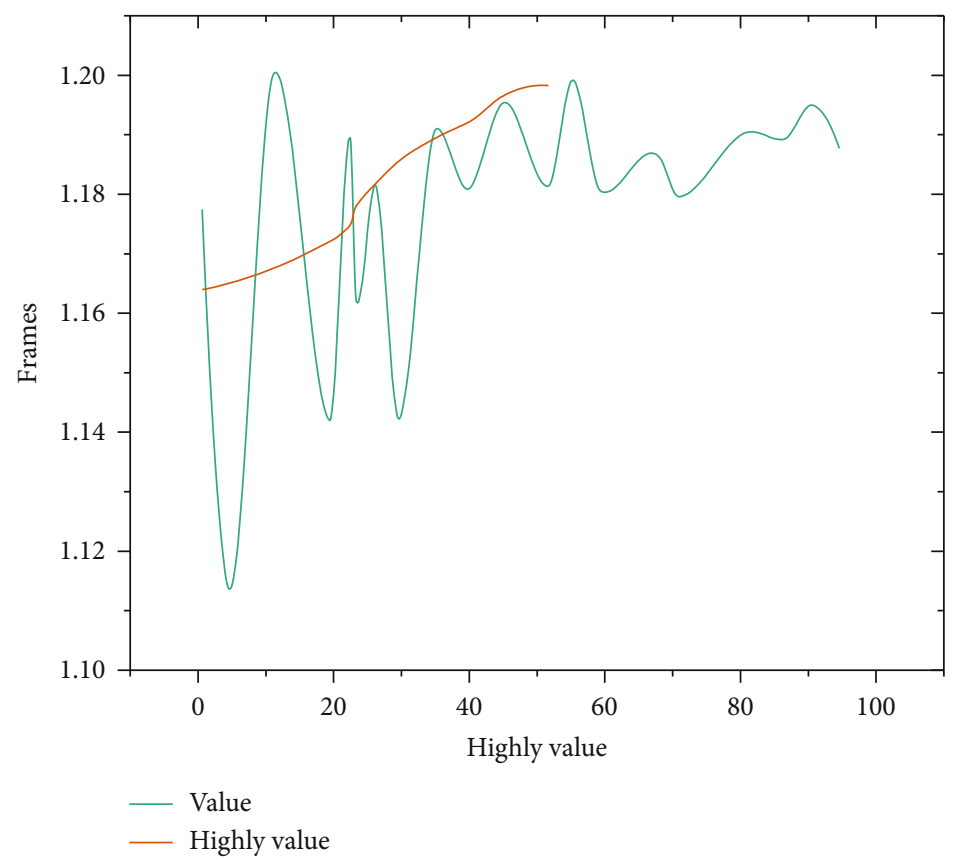

FIGURE 13: High-value agricultural line chart.

agricultural products and enhance the customer experience and customer stickiness of agricultural product consumers. In this process, the agricultural Internet platform has developed into the core of the industrial chain, which combines the material flow, capital flow, and information flow of the entire industrial chain, making the entire industrial chain "symbiotic, win-win, and mutually beneficial" and forming a perfect, extremely open information. As the founder of the agricultural Internet ecosphere, agricultural leading enterprises gradually develop to specialization, flatness, and integration, providing financial investment, financing, and online payment services for the whole industry upstream and downstream.

In the process of the establishment and development of the ecological circle, agricultural Internet finance will run through every process of agriculture, including the sale and purchase of agricultural materials, the whole process of agricultural production, the sale of agricultural products, and other links, so as to make comprehensive agricultural materials, e-commerce, and similar finance. The integration of service, on-line and off-line agrochemical service, has become the inevitable trend of the comprehensive development of modern agricultural industry.

\section{Data Availability}

All data can be obtained from the author.

\section{Conflicts of Interest}

We declare that there is no conflict of interest regarding the publication of this paper.

\section{Acknowledgments}

This work is supported by the Project of National Social Science Fund of China (Grant No. 17BZZ050).

\section{References}

[1] L. Huang and P. Liu, "Key technologies and alogrithms' application in agricultural food supply chain tracking system in E-commerce," in Computer and Computing Technologies in Agriculture VII. CCTA 2013. IFIP Advances in Information and Communication Technology, vol 420, D. Li and Y. Chen, Eds., pp. 77-133, Springer, Berlin, Heidelberg, 2015.

[2] J. H. Fang, H. X. Luo, L. L. Wang, and S. Chen, "Study on tropical agricultural mobile e-commerce system in Hainan," Applied Mechanics \& Materials, vol. 7, no. 5, pp. 631-632, 2014.

[3] Z. Tianqi, "Paths for upgrade and transformation of ecommerce of China's fresh agricultural products based on whole industry supply chain," Asian Agricultural Research, vol. 4, no. 8, pp. 1-4, 2017.

[4] S. P. Adegoke and M. M. Osokoya, "Socio-economic background and access to internet as correlates of students' achievement in agricultural science," International Journal of Evaluation \& Research in Education, vol. 9, no. 2, pp. 1-4, 2015.

[5] M. Pouratashi and M. Mokhtarnia, "Investigating factors influencing use of internet by agricultural faculty members for educational and research activities," AfrrevStechAn International Journal of Science \& Technology, vol. 3, no. 2, pp. 17, 2014.

[6] Z. Wang, J. Huang, and B. Tan, "Managing organizational identity in the e-commerce industry: an ambidexterity perspective," Information \& Management, vol. 50, no. 8, pp. 673-683, 2013. 
[7] M. Yadav and Z. Rahman, "Measuring consumer perception of social media marketing activities in e-commerce industry: scale development \& validation," Telematics \& Informatics, vol. 34, no. 7, pp. 1294-1307, 2017.

[8] L. Liu, K. Li, and Z. Liu, "A capacitated vehicle routing problem with order available time in e-commerce industry," Engineering Optimization, vol. 49, no. 3, pp. 449-465, 2017.

[9] D. M. Liverman, "Drought impacts in Mexico: climate, agriculture, technology, and land tenure in Sonora and Puebla," Annals of the Association of American Geographers, vol. 80, no. 1, pp. 49-72, 1990.

[10] C. M. Pittelkow, L. Q. Xiang, and B. A. Linquist, "Productivity limits and potentials of the principles of conservation agriculture," Nature, vol. 517, no. 7534, pp. 365-368, 2015.

[11] S. Interpreters, "Fao - food and agriculture organization of the united nations," Science, vol. 118, no. 3077, pp. 3-3, 2013.

[12] W. Zhang, T. H. Ricketts, C. Kremen, K. Carney, and S. M. Swinton, "Ecosystem services and dis-services to agriculture," Ecological Economics, vol. 64, no. 2, pp. 253-260, 2007.

[13] M. Bustamante, C. Robledo-Abad, R. Harper, C. Mbow, N. H. Ravindranath, and F. Sperling, "Co-benefits, trade-offs, barriers and policies for greenhouse gas mitigation in the agriculture, forestry and other land use (afolu) sector," Global Change Biology, vol. 20, no. 10, pp. 3270-3290, 2015.

[14] G. P. Robertson, V. H. Dale, O. C. Doering et al., "Agriculture. Sustainable biofuels redux," Science, vol. 322, no. 5898, pp. 4950, 2008 .

[15] D. J. Mulla, "Twenty five years of remote sensing in precision agriculture: key advances and remaining knowledge gaps," Biosystems Engineering, vol. 114, no. 4, pp. 358-371, 2013.

[16] M. Y. Siddiqui and A. Gir, "Integration of policy and reputation based trust mechanisms in e-commerce industry," International Journal of Computer Applications, vol. 110, no. 8, pp. 15-19, 2015.

[17] D. Lagakos and M. E. Waugh, "Selection, agriculture, and cross-country productivity differences," American Economic Review, vol. 103, no. 2, pp. 948-980, 2013.

[18] P. Collier and S. Dercon, "African agriculture in 50 years: smallholders in a rapidly changing world?," World Development, vol. 63, no. C, pp. 92-101, 2014.

[19] G. C. Nelson, H. Valin, R. D. Sands et al., "Climate change effects on agriculture: economic responses to biophysical shocks," Proceedings of the National Academy of Sciences of the United States of America, vol. 111, no. 9, pp. 3274-3279, 2014.

[20] H. Zheng, W. Guo, and N. Xiong, “A kernel-based compressive sensing approach for mobile data gathering in wireless sensor network systems," IEEE Transactions on Systems, Man, and Cybernetics: Systems, vol. 48, no. 12, pp. 23152327, 2017.

[21] Z. Huang, X. Xu, J. Ni, H. Zhu, and C. Wang, "Multimodal representation learning for recommendation in internet of things," IEEE Internet of Things Journal, vol. 6, no. 6, pp. 10675-10685, 2019.

[22] H. Liang, D. Zou, Z. Li, K. Muhammad Junaid, and Y. Lu, "Dynamic evaluation of drilling leakage risk based on fuzzy theory and PSO-SVR algorithm," Future Generation Computer Systems, vol. 95, pp. 454-466, 2019.

[23] Z. Liu, B. Hu, B. Huang, L. Lang, H. Guo, and Y. Zhao, "Decision optimization of low-carbon dual-channel supply chain of auto parts based on smart city architecture," Complexity, vol. 2020, Article ID 2145951, 14 pages, 2020.

[24] Y. Zhang, R. Zhu, Z. Chen, J. Gao, and D. Xia, "Evaluating and selecting features via information theoretic lower bounds of feature inner correlations for high-dimensional data," European Journal of Operational Research, vol. 290, no. 1, pp. 235-247, 2021.

[25] H. Liang, A. Xian, M. Min Mao, P. Ni, and H. Wu, “A research on remote fracturing monitoring and decision-making method supporting smart city," Sustainable Cities and Society, vol. 62, article 102414, 2020.

[26] Y. Zhou, D. Zhang, and N. Xiong, "Post-cloud computing paradigms: a survey and comparison," Tsinghua Science and Technology, vol. 22, no. 6, pp. 714-732, 2017. 